\title{
The Divisions of EPS: The Early Years
}

From the left, A. Zichichi, E. Schatzman and O.S. Heavens at the 1978 General Conference in York.

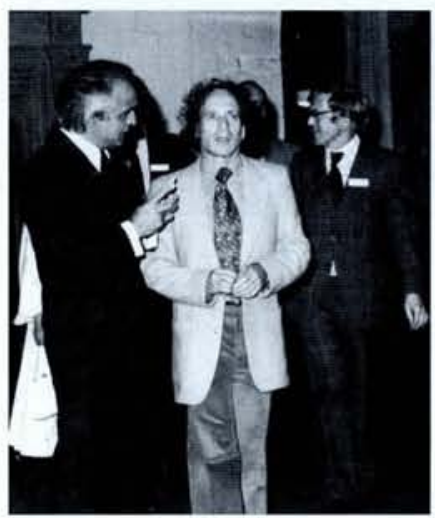

\section{Astrophysics}

The Physics in Astronomy Division developed from an initiative by E. Schatzman from Paris following discussions at conferences in 1970. An interim steering committee prepared a proposal which was accepted in principle by the October 1970 Council. It was felt that the International Astronomical Union among others bodies would object to the title "Astronomy" so Council recommended the name Physics in Astronomy to the interim Board. The initial proposal, however, had referred to Astronomy and Astrophysics as Physics in Astronomy would "give to many people the feeling they are excluded", thus hindering links between the two disciplines.

The Division held its inaugural meeting in Paris in February 1972 with 100 participants and high hopes. Members indicated that they wanted the name changed to reflect the main interests, so the Division's draft statutes submitted to Council in 1972 were for an Astronomy and Astrophysics (A\&A) Division. The label stuck, especially since the EPS Executive had received an application for a High Energy and Astrophysics Division.
The inaugural meeting discussed proposals to form Sections for solar physics and cosmic rays, but according to a report in Europhysics News by M.J. Rees from Cambridge, "formal steps were premature". Associations for solar observatories and radio astronomy were to come together in 1974 to organize the first European Solar Physics Conference in Florence in March 1975. A European Solar Meeting Organizing Committee (ESMOC) was formed at the conference, one of its tasks being to prepare a Solar Physics Section with a provisional board identical to ESMOC. Draft statutes were prepared and Council approved the Section in March 1976. The Section gathered full momentum, leaving its parent somewhat behind as the Division Board preferred to work through existing conferences. Indeed, the Section has represented the Division since 1992 pending finalised arrangements for a new joint Astrophysics Division with the European Astronomical Society created, with support from the Division, in 1991.

P.G. Boswell

\section{Atomic and Molecular Physics}

Discussions at a conference in Oxford in July 1970 of a proposal to form a Division for atomic and molecular physics were launched by G.W. Series from Reading, who chaired his national section for atomic physics. In the end, an Atomic Physics Division (APD) was proposed, but the Executive in January 1971 felt there was too much overlap with other Divisions and asked for a reformulation. Discussions between the various Boards concerned avoided any serious conflict, some members even signing a declaration that the activities of one Division should not limit those of another. The revised proposal still covered a broad range of topics spanning atoms to astrophysics. A few of the interests were already well served by the very active Division for atomic spectroscopy (called the European Group for Atomic Spectroscopy, EGAS), chaired by A. Kastler from Paris, which was organizing the wellknown EGAS annual conferences. The EGAS name had been chosen during discussions on international collaboration at a colloquium in October 1968, and the Group kept it on becoming a Division in 1969.

The outcome was an indication from EGAS that it might team up with the APD, while other Divi-

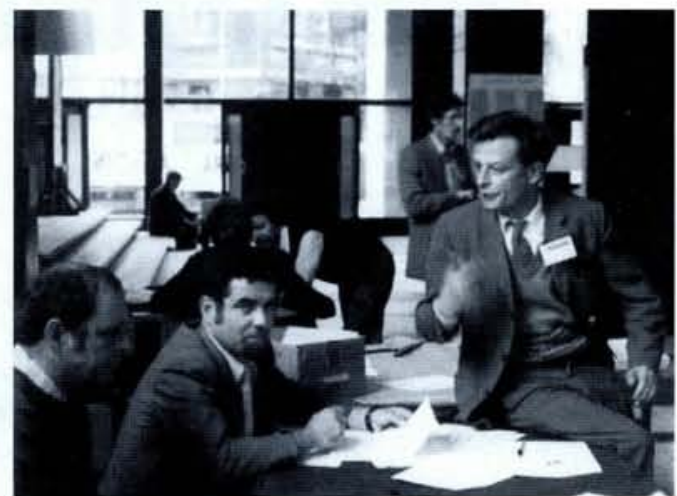

sions wished to remain separate. Council accepted the proposed Division in March 1971 and by September, I reported as Chairman that two Sections (Molecular Physics and Electronic and Atomic Collisions) would be put forward. The APD Board announced in October 1972 that it planned to appoint ex offico the Chairman and Secretaries of these two new Sections, with EGAS becoming the Atomic Spectroscopy Section, this Sectional structure, and indeed the name "Section" having been recommended following a survey by the EPS Executive Committee. A fourth Section (Chemical Physics) was formed in 1975 following an initiative by I. Kovács from Budapest.

By the end of 1972, the APD had 380 members and was already actively engaged in sponsoring and organizing conferences and schools. As was intended, the Division undoubtedly played an important rôle in stimulating relations with the other fields, and in developing cooperation in an area which has been growing very rapidly since the 1960's, thanks to new experimental techniques and theoretical tools.

Council accepted in 1981 a proposal to change the name to the Atomic and Molecular Physics Division (AMPD) to reflect broadened interests. Today, in addition to numerous topical conferences, workshops and schools, the AMPD organizes the European Conference on Atomic and Molecular Physics (ECAMP), the European Sectional Conference on the Atomic and Molecular Physics of Ionized Gases (ESCAMPIG), the Muon Catalyzed Fusion conference, and the European conference on atomic spectroscopy (EGAS). It also helps organize the European conference on the dynamics of molecules (Molec) and the International Conference on the Physics of Electronic and Atomic Collisions (ICPEAC). In terms of the number of members, it is now the Society's second largest Division.

H. van Regemorter

Observatoire de Paris, Meudon (Chairman, 1971-74)
M. Barat (in the centre), Chaiman of the Atomic and Molecular Phy sics Division, 1989-92, with $\mathrm{H}$. van
Regemorter (on the right) at the 10th ICPEAC in Paris in 1977. 


\section{Condensed Matter}

G. Bernardini stressed in 1968 that "the formation of EPS is a demonstration of the determination of scientists to collaborate as closely as possible in order to make their contribution to the strength of European cultural unity". He went on the say that: "it is often quite hard to convert the idea of collaboration into something really effective, rather than an Utopia". Even at the very beginning of EPS, the physics of condensed matter was recognized as a key discipline and the Inaugural Conference in Florence in April 1969 had this topic as one of the points of discussion. A subject of great interest in its own right, condensed matter constitutes a major bridge between physics and industrial applications and industry. After 25 years, we can ask ourselves as solid-state physicists what the Condensed Matter Division (CMD) of EPS has contributed, and whether or not the EPS founding fathers were Utopians.

The Division is today by far the largest, counting as members almost half of the EPS membership. Truly interdisciplinary, condensed matter covers in principle the physics of liquids and solids so it enjoys close contact with fields such as statistical mechanics, chemical physics, polymers and biophysics, computational physics, and physics at high pressures. The goals of the EPS Divisions were at first defined in rather general terms, and the CMD's "immediate aims" in 1969, as outlined by an ad hoc steering committee under S.F. Edwards from Manchester (who moved to Cambridge in 1972), were to rationalize conferences, coordinate summer schools, and promote personnel services, i.e., to extend existing bilateral scholarship and fellowship schemes, inter-laboratory links and personal links, and suchlike to an international level. To understand the goals one must appreciate that in 1969 there were many specialist meetings on the same topic taking place in Europe at the same time outside existing frameworks such as IUPAP. Second, contacts between scientists and institutions on the European level were rare. Indeed, European scientists often had a stronger interaction with American colleagues than with those at home, a situation which was reinforced by the tradition of hospitality towards European (and other) scientists visiting the USA for a few weeks, or even years (whereupon many stayed). Within Europe, invitations between colleagues were the exception. If today all this has changed, and interaction at the European level is now well established, it is because many have contributed. And the EPS has certainly played a key rôle.

The Division approved by Council in 1969 was initially managed by a Board nominated by national societies with Edwards as Chairman. A year later it was decided to implement the Division's proposal to become a confederation of a limited number of Sections modelled on the well-established European High Pressure Research Group (EHPRG). The Division's statutes, approved by Council in 1972, recognized this special structure whereby Sections would help the Board in its work and provide "some organization devoted to each area". A compromise had in effect been found in order to reconcile "centralization versus freedom of Sections". The Board was reconstituted, with the Section Chairman and a representative from EHPRG as members. From 1986 on, three representatives of the individual members were directly elected to the Board to establish a closer relationship with members.

Discussion at the first CMD general meeting in Florence in September 1971 helped in the setting

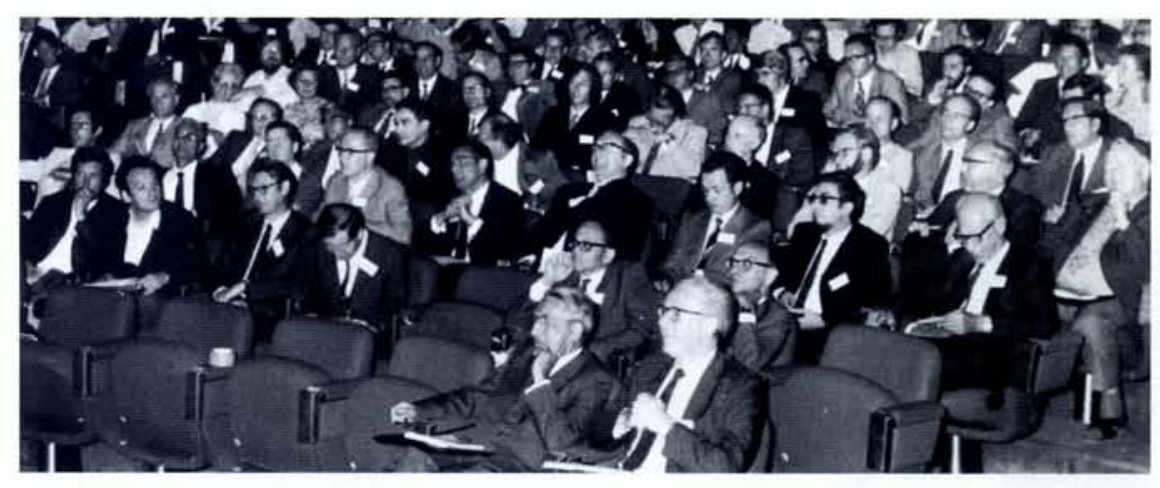

up of the Sections. By the end of 1972 there were six in all, including Low-Temperature Physics which had originally been formed as a Division. The general conference and its successors (in 1974 and 1977) concentrated on two subjects so they were in essence topical meetings. The Sections had also started to organize several activities, mostly conferences, starting with a meeting on magnetism in June 1970.

Inspired by The American Physical Society's very large "March" meeting on solid-state physics, the main activity of the Division since 1980 , in what some called a "new beginning", has been to organize the annual General Conference of the Condensed Matter Division of EPS. This event had the specific goal of creating a forum where established as well as young scientists starting out their research careers could present their work to colleagues. At the same time it would give every physicist a clear view of the state-of-the-art of condensed-matter physics. Even though conferences held before 1986 covered a limited number of topics, they have always attracted more than 600 participants, including the first event (in Antwerp in April 1980) which surprised some observers. This success, fundamentally since the beginning, is highlighted by the plenary talks given by a string of European solid-state physicists who have won Nobel Prizes, and since 1982 by the awarding of the Hewlett-Packard Europhysics Prize at the conference. The deployment of a Programme Committee and an International Advisory Committee each with some $60 \mathrm{mem}$ bers, all distinguished and from throughout Europe, clearly induced a snow-ball effect.

But the annual conference has had to face some problems. For example, what should be done to attract more young scientists and possibly to enhance the scale somewhat so that (like the APS "March" meeting) each sub-field becomes almost a small "conference within a conference". As the unification of Europe proceeds, the CMD annual conference will prosper, benefitting from initiatives such as the European Community's Human Capital and Mobility Programme that aim to foster interaction between scientists. Although some national meetings may attract the same or larger numbers of participants (including many students as locations are often easily accessible and inexpensive), the CMD event will continue to act as a bond between scientists. The fact that each year a new team of colleagues offers to organize the next event confirms this.

It would be fair to say that when one compares European physics in 1993 with what it was like 25 years ago, some dramatic changes have occurred and the EPS as a whole and its Divisions have contributed much to the revitalization.

J.T. Devreese University of Antwerp (Chairman, 1980-86)
The opening of the First European Conference on the Physics of Condensed Matter at the Palazzo dei Congressi in Florence in September 1971 Shown seated in the front row are A. Guinier (on the left) and S.F. Edwards.

The Abstracts Booklet for the first Condensed Matter conference.

rical sociei DIVISION OF CONDENSED MATTE

First

European Conference on the Physics of Condensed Matter

M.17 Septenter 107r

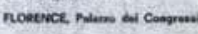




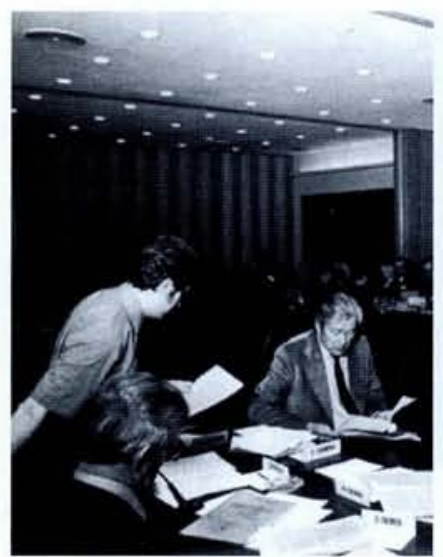

Facing the camera, G. Charpak, Secretary of the High Energy and Particle Physics Division, 1972-76, at the 1974 Council meeting held at the Institut Battelle, Geneva.

\section{High Energy and Particle Physics}

It is no surprise that high energy and particle physicists were prominent amongst the founding fathers of the EPS in 1968. Since the early 1950's, cosmic-ray research, a major source of particle physics data, had been pursued by collaborations which brought together scientists from across Europe, many of whom saw this internationalism as more than just an incidental benefit. The same pan-European spirit which inspired them flourished at CERN; when the Society was founded, CERN had been for more than a decade a focal point for the particle physics community. Indeed, Bernardini, the Society's first President, had been a member of the CERN Directorate in the early 1960 's. Perhaps the only surprise is that it took a year or so before the Division itself was established, separate from Nuclear Physics in what was to be a harmonious coexistence.

The aims and activities of the High Energy and Particle Physics (HEPP) Division proposed by the steering committee which met in February 1970 to set an agenda still serves today with very little change. The Division was expected to coordinate views on research facilities (the burning issue at that time was CERN's proposed $300 \mathrm{GeV}$ accelerator), to organize conferences, including small conferences on specialized topics, and to assist in the coordination of advanced education. When Council approved the establishment of the Division later that year, the steering committee (which had been joined by A.M. Baldin from the USSR, who was, however, never able to attend its meetings) became the Board, with the nuclear spectroscopist P. Preiswerk as its first Chairman A. Zichichi succeeded as Chairman when Preiswerk died in 1972.

The Division's first Europhysics conference had been successfully held in Bologna the previous year, and the fledgling Division had some 50 members. By this time the international "Rochester" high-energy conferences under the auspices of IUPAP had settled down to a biennial cycle held in the even years. Starting with the 1973 conference held in Aix-en-Provence, the EPS HEPP Divisional conference has become the major international meeting in the intervening odd years. A very satisfactory format involving

\section{Nuclear Physics Division}

As is usual with such matters, the informal start of the Nuclear Physics Division (NPD) goes back to several private discussions, some of which took place during the Inaugural Meeting of EPS in 1968. Possibilities were later discussed during a conference in Heidelberg in 1969, where those present preferred the formation of a Division covering both nuclear physics and particle physics - an early sign of today's sub-atomic physics spirit. Subsequent discussions with high-energy physicists, however, made it clear that time was not yet ripe for a unified Division. Nuclear physicists therefore proposed to go it alone, but of course left the final decision to Council. Council ruled in favour of a separate Nuclear Physics Division in early 1970; it was to be brought to life by a steering committee chaired by L.L. Green who became the first Board Chairman.

Putting aside the controversy over the Division's statutes, where the NPD was a Division avant la lettre in the sense that the approval of its Statutes had to wait until EPS had established general rules for Divisions, the first problem discussed by the Board was the proliferation of jour- typically, three days of parallel sessions, and after a weekend in which rapporteurs work hard to summarise what they have heard, the meeting reconvenes for plenary reports and major invited talks. Attendance has been based on an allocation of places to national conveners, with typically around 600 participants. Emphasis is placed on encouraging participation by young physicists, for whom the Division has made available some financial assistance; it is from these young physicists that the scientific secretaries to the parallel session organizers are chosen, so the benefits are reciprocal.

The Division's conferences are not only scientifically successful but also provide income. This has been used to support some important initiatives. Aside from bursaries for both its own and the EPS general conferences, surpluses have been used to establish a fund to help strengthen the small Portuguese high energy community, for example, by providing travel funds. The Division has also helped the Society as a whole to weather financial difficulties on two occasions. More recently, these funds have enabled the Division to establish the biennial EPS High Energy and Particle Physics Prize, the first being awarded in 1989 to Georges Charpak, admirably anticipating the subsequent award of the 1992 Nobel Prize for Physics (the 1991 and 1993 winners are Nicola Cabibbo and Martinus Veltman, respectively).

High energy and particle physics has had a productive and vigourous life this past 25 years, and European physicists have played a prominent rôle. The EPS Division has helped to promote this, and has seen its numbers grow to some 600 IOM's. Our International Europhysics Conference on High Energy Physics is now of global, not just pan-European, importance. It might be noted that the Division has also promoted the establishment of a biennial international accelerator conference, and every year it approves the recognition of numerous schools and the like. We have benefitted as a community from the EPS involvement, and have as a community played a positive rôle in the Society, not least by having supplied more than our share of Presidents.

\section{J.M. Charap}

Queen Mary and Westfield College, London (Secretary, 1981-84)

nals and conferences. The Division decided to concentrate on conferences, probably because journals moved too slowly. A European conference scheme was set up involving a series of large Divisional conferences ( $>300$ participants), smaller topical conferences $(\approx 100$ participants, this number being primarily limited by the choice of the topic), study conferences $(<100$ participants), and summer schools. The first major conference took place in Aix-en-Provence in June 1972 shortly before the Division was officially formed. The scheme worked remarkably well for many years, and the coordination did indeed reduce the number of conferences.

The annual study conferences were inspired by the Gordon conferences in the US. The idea of starting them was warmly welcomed by the EPS Council, except for the name since H.B.G. Casimir, the EPS President at the time, considered it to be a contradictio in terminus. Moreover, a few senior colleagues pointed out that they were not new, for Europe. Nonetheless, the name has remained. EPS agreed in 1990 to incorporate Divisional study conferences, wherever possible, within the "Gordon-style" European Research Conferences (ERC) organized by the European 
Science Foundation with support from the European Community. A Working Group for the ERC's was formed within the EPS Action Committee on Conferences to coordinate proposals with the Divisions and to present them to the ERC steering committee.

Another interesting issue during the early years involved finances. The NPD felt that part of the EPS income should go directly to the Divisions. After a few warm discussions in Council it was decided that the Divisions should receive a fixed amount per member each year. This seed money was definitely an incentive for the subsequent increase of the number of Individual Ordinary Members (IOM's). A few years later, when EPS happened to run into some financial problems, and the Divisions secured some funds by organizing profitable conferences, any commitments ended without much Council discussion.

Many other points of discussion might be mentioned. Some of them continued for 25 years, others pop up more or less regularly. In my opinion, however, the most important achievement is the creation of a spirit of broad and open col-

\section{Plasma Physics}

Some 50 years ago, plasma physics appeared to be a rather limited and specialized branch of physics. However, it soon became obvious that the interaction between electrically conducting matter and electromagnetic fields constitutes an important area of research with many applications in cosmic physics and geophysics, controlled thermonuclear fusion, space research, power generation, plasma chemistry, and the technical uses of gaseous discharges. In fact, plasma physics describes the "fourth state of matter" which includes practically the whole field of classical physics, and also considerable parts of atomic and nuclear physics. In addition to its applications, plasma research helps deepen the understanding of physics as a whole; its manysidedness stimulates and enriches the interaction between different branches of physics, and between basic research and technical development.

International conferences and symposia on plasma physics and its application to cosmic phenomena and controlled thermonuclear fusion were organized at an increasing frequency, and on an growing scale, from the beginning of the 1950 's. At the United Nations conference on the peaceful uses of atomic energy in Geneva in 1958, a number of special sessions were devoted to controlled fusion research. A European study group on plasma physics and thermonuclear fusion was established in conjunction with the conference, and it was to organize meetings, among them conferences held in 1963 and 1964. The growing interest in, and importance of, plasma physics led to the meetings of the study group being transformed into the European Conference on Controlled Fusion and Plasma Physics, held in Munich in 1966. in Stockholm in 1967, and in Utrecht in 1969. The committee of a European Plasma Physics Group under the chairmanship of P.C. Thonemann was formed at the Stockholm meeting, and I took over from Thonemann in 1969.

Motivated not only by the importance of plasma physics, but also by the large resources which are involved in plasma research, the commmittee decided at the Utrecht conference to apply to become a "Division of Plasma Physics" within EPS. The application was approved by Council in July 1969 and the Division Board, with myself as Chairman, was complete the following October. A preliminary version of laboration among European nuclear physicists. In the second half of the 1960's, when EPS and its NPD were founded, this was not self-evident. I would like to illustrate the point with a personal recollection which also took place about 25 years ago. The Netherlands' Physical Society (NNV) received a letter from the German Physical Society (DPG) suggesting a bilateral cooperation. The question was discussed carefully and very seriously by the NNV Board, which finally decided that, by way of experiment, Dutch nuclear physicists should contact their German colleagues. After all, many of them had got to know each other in the US. It probably cannot be found in the minutes, but I am pretty sure that this positive reaction was at least partly due to the fact that the DPG's letter was written in English. The experiment resulted in a combined meeting of the DPG and NNV nuclear physics sections that was the first in a series of biennial combined meetings, which continue to the present day.

\section{C. van der Leun}

Rijksuniversiteit te Utrecht (Chairman, 1973-78)

Division Rules were prepared at an early stage by the Board. They aimed to complement the Constitution and By-laws of EPS by covering issues specific to the Division. These issues were mostly connected with the coordination of work within the many existing sub-fields of plasma physics, procedures for electing the Board, and the way events should be organized.

The Division's function was to stimulate plasma research in Europe and scientific cooperation between countries and institutes in both eastern and western Europe. While the Division was formed mainly as the result of initiatives by fusion physicists, it was always intended that other branches of plasma physics should participate in activities involving the organization of meetings of all types and the creation of efficient European journals in plasma physics. Consequently, every effort was made to ensure that all branches of plasma physics were represented.

Events are organized and coordinated by the Board in collaboration with local organizing committees, with help from the Conference Committee of EPS, and an EPS student exchange scheme. The Division's first major conference was the 4th European Conference on Controlled Fusion and Plasma Physics in 1979. It was very successful and attracted about 360 participants from 19 countries. The first European Conference on Cosmic Plasma was organized at Frascati in September 1971. This represented an important step forward in the development of the Division as it was undertaking for the first time formal actions in the field of cosmic plasma physics. Other initiatives included a conference on quiescent plasmas in Denmark held the same month, and two series of summer schools started in 1972, the year I handed over the Chairmanship to P. Vandenplas.

It is perhaps interesting to remark that one of the Board's first activities was to take part in an assessment in 1970 of controlled thermonuclear fusion research by an international panel under the auspices of the International Atomic Energy Agency. The Board also argued in favour of retaining the European Space Research Organization's Institute for Basic Scientific Research (ESRIN) at Frascati when the Council of ESRO (a fore-runner of the European Space Agency) proposed its closure in July 1971.

\section{B. Lehnert}

Royal Inst. of Tecnology, Stockholm (Chairman, 1969-72)

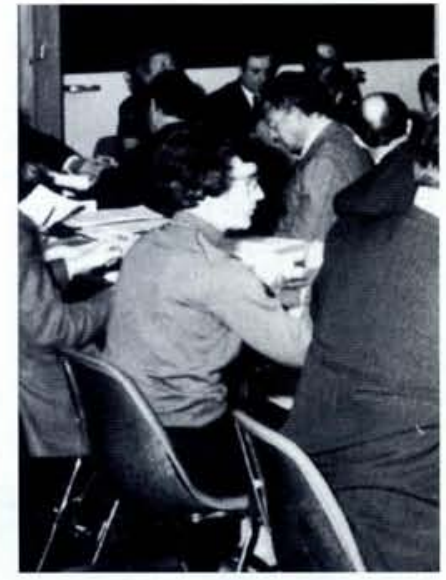

Verena Mayer from Zurich, who chaired the Nuclear Physics Division from 1981 to 1982 , at the 1974 Council meeting.

The programme for the Plasma Physics Division's second European Conference on Cosmic Plasma Physics.

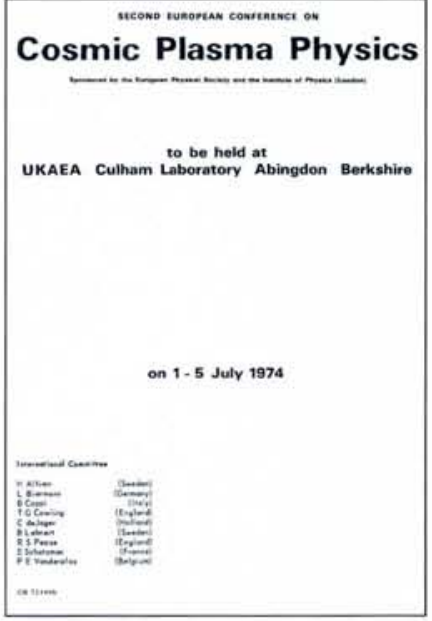




\section{Quantum Electronics and Optics}

The initiative to form a Quantum Electronics Division (QED) essentially started with K.P. Meyer's interest in establishing a European laser institute at his laboratory in Bern. He called a meeting of a steering committee for a future Division to discuss European collaboration. It took place in Bern in February 1968, and a remarkably complete range of possible activities was scrutinized. An interim steering committee to promote further action chaired by Meyer was nominated, with national societies being invited to put forward delegates. The original committee was EPS photographed at the Council Meeting in Paris in February 1970. Left to right, K.P Meyer (Quantum Electronics), S.F. Edwards (Condensed Matter), A. Kastler (Atomic Spectroscopy), C.J. Gorter (Low-Temperature Physics), and B. Lehnert (Plasma Physics).

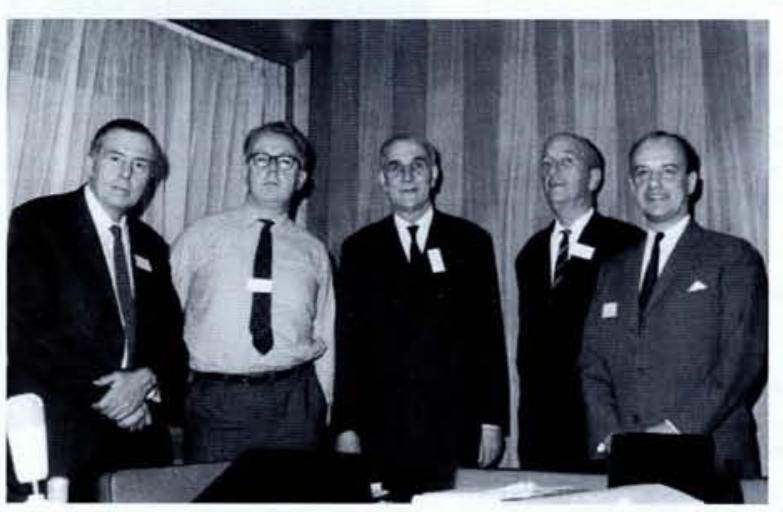
mainly drawn from the European representatives on the programme committee of the 5th International Quantum Electronics Conference (IQEC-5) held in Miami in 1969 as the American partners wanted a more clear-cut European body with which to coordinate the future meetings (IQEC had stayed mainly in the USA but was seeking to go abroad more often). Consequently, S.A. Ramsden from Hull wrote to the Chairman of the Joint Council on Quantum Electronics in March 1969 on behalf of the interim committee to ask if the future QED could help. It was not until the March 1974 Council that Ramsden, who had been elected the first Division's Chairman in 1971, could report that the QED had been asked to organize the 1976 IQEC. The Division had meanwhile started its own meeting, passing the 100 participants barrier at the third meeting in 1971. A new series of annual Divisional conferences (the European Quantum Electronics Conference, EQEC) was started in 1988, and its schedule began to be coordinated with that of $I Q E C$ in 1989.

In 1991, the QED took over the activities of the Optics Division (formed in 1982) when the Optics Board resigned upon the creation of the European Optical Society. Members voted for a name change (Quantum Electronics and Optics Division) to reflect the natural inclusion of optical physics. The Division is presently heavily engaged in organizing the fifth $E Q E C$ (in Amsterdam next August) as a "back-to-back" meeting with a European version of the Optical Society of America's very successful Conference on Lasers and Electro-Optics (CLEO) to be called CLEOEurope: European Conference on Lasers and ElectroOptics).

P.G. Boswell

\section{Constituting the Divisions}

Two years after the official inauguration of EPS, Laurens Jansen, the Secretary, wrote: "It is probably not to be exaggerated to state that a large part of the European community of physicists judges the desirability of joining EPS first and foremost on a professional basis." He echoed what had been said from the outset, when one of the working groups at the Pisa meeting in April 1966 envisaged the creation of specialist groups to carry out the Society's work. But combining professional motivations with the desire to create a European community active in all aspects of physics was not going to be straightforward.

At its January 1968 meeting, the Steering Committee to form EPS received reports that ad hoc groups for solid-state physics under S.F. Edwards and for quantum electronics under K.P. Meyer had already started informal discussions, while a 35-member strong Plasma Physics Group chaired by P.C. Thonemann had even gone so far as to collect membership fees. L. Cohen, the Secretary of The Institute of Physics and The Physical Society (IPPS) in London, felt the EPS Constitution needed "to give subject groups a sort of legal status within the Society" as this would provide "the most useful possibilities for their operation". He then raised some of the obvious questions. Should EPS take the initiative to form groups or wait for a "spontaneous demand"? How were the groups to be financed, organized and represented in view of his own society's experience that they need not be permanent? Participation in publishing activities was a concern, and Cohen was no doubt worried that interesting possibilities could drift away.

H. Curien from Paris proposed that the principle criterion for the choice of topics at the Inaugural Conference being planned for 1969 should involve the promotion of specialized groups. Bernardini argued this could be done without excluding any field of physics by having the sessions focus on the points at which fields "were growing in a more promising manner as this would allow existing groups to promote the formation of new ones".

\section{Within the By-Laws}

The list of potential candidates was enlarged at the Steering Committee's next meeting in May 1967 by the inclusion of groups that had formed independently of the moves for an EPS (notably, the European Group for High Pressure Research - EGHPR - and the Groupement Ampère). Secondly, J. de Boer from Amsterdam and his colleagues had circulated a letter seeking support for the formation of a low-temperature physics group, with a main task of organizing a general low-temperature physics conference ("group" having been chosen to emphasize close relations with other branches of physics, whereas the term "division" would "break the unity of physics"). However, it was Edwards who went to the heart of the matter by urging the setting up of several Divisions "charged with the business of acting as a continuity in European conferences, and having the interactions with EPS defined within the context of the Society's By-laws".

A working group on the constitution under E.G. Rudberg was asked to take up the task of drafting By-laws that would be adopted by the first Council. A working draft was ready for the Society's plenary meeting held immediately before the inauguration at CERN on 26 September 1968 , but it was incomplete as only the rules relating to individual membership had been agreed. This situation naturally invited further discussion. De Boer questioned the need for specialized divisions, continuing to feel there was some truth in the literal meaning of the word "division". How this view was to be reconciled with his community's interest in organizing a conference was unclear.

J. Friedel from Paris argued that EPS should move quickly to define its main divisions based say on categories of materials, with sub-divisions 